\title{
EFEITOS FISCAIS DA INFLAÇÃO NA ANÁLISE DE PROJETOS
}

\author{
Antonio Carlos Teixeira Álvares \\ Engenheiro de Produção pela Escola Politécnica da USP, Professor do \\ Departamento de Produção e Operações Industriais da FGV/EAESP e \\ Diretor Superintendente da Brasilata S.A. Embalagens Metálicas.
}

E-mail: teixeira@fgvsp.br

\section{RESUMO}

A análise de projetos industriais, cujo horizonte de planejamento usualmente varia de cinco a vinte anos, normalmente está sujeita a fortes condições de incerteza. Uma importante condição de incerteza é o fenômeno inflacio-

- nário, contornado pela Engenharia Econômica com 0 artifício de se trabalhar com fluxos de caixa em valores constantes e juros reais, desconsiderando os efeitos da inflação. Entretanto, nos casos das análises feitas depois do imposto de renda, os montantes reconhecidos como despesas de depreciação estarão monetariamente desvalorizados pela inflação. A fim de demonstrar a penalidade para os gastos com investimentos, introduzida pelo fenômeno, é utilizado o caso clássico compra versus aluguel, sendo realizada uma análise de sensibilidade à

- variação das taxas de inflação. Como conclusão, são sugeridas mudanças na metodologia tradicional de análise

- de investimentos em ambiente inflacionário. 


\section{CONSIDERAÇÕES INICIAIS}

A análise de projetos, especialmente os industriais, cujo horizonte de planejamento usualmente varia de cinco a vinte anos, normalmente está sujeita a fortes condições de incerteza. Como exemplos mais comuns, devem ser mencionadas as previsões sobre o comportamento futuro dos mercados e as eventuais mudanças tecnológicas, as quais, em casos extremos, podem causar rupturas definitivas com o produto existente (fax $\mathrm{x}$ telex; computador pessoal $\mathrm{x}$ máquina de escrever e vários outros casos do gênero).

Além disso, a existência do fenômeno inflacionário significa uma incerteza definitiva, uma vez que a inflação está presente em caráter permanente em todos os países desenvolvidos do planeta desde a Segunda Grande Guerra (Álvares, 1998a). Sob outro aspecto, a inflação normalmente representa um grau ainda maior de incerteza uma vez que, se as previsões de longo prazo, no que se refere à demanda ou às novas tecnologias, são difíceis, a previsão da inflação futura é, de acordo com Jones (1982), mera especulação.

Segundo Álvares (1998a, p. 5), a evolução dos níveis de preço ao consumidor nos países desenvolvidos indica que as menores taxas médias anuais de inflação no período de 1975 a 1995 foram as do Japão, da Suíça e da Alemanha (em torno de $3,0 \%$ ), seguidas das taxas dos EUA (5,3\%), França (6,2\%) e Reino Unido $(7,6 \%)$, enquanto a Itália apresentava média anual de $10,2 \%$ no período.

Considerando-se apenas o ano de 1997, quando as taxas de inflação nas economias centrais foram muito baixas, as taxas médias anuais foram de $1,7 \%$ no Japão, $1,8 \%$ na Alemanha e $2,4 \%$ nos Estados Unidos (FMI, 1998).

Tal fato corrobora a afirmativa de que a inflação, ainda que em proporções reduzidas, faz parte do cotidiano dos países desenvolvidos, sendo razoável supor que, devido às suas condições estruturais, o Brasil, cuja inflação após o advento do Plano Real vem se situando em patamares civilizados, deverá conviver com taxas provavelmente superiores - no mínimo equivalentes - às observadas nas economias centrais.

\section{INFLAÇÃO E ENGENHARIA ECONÔMICA}

Segundo Jones (1982, p. 132), a Engenharia Econômica trabalha com o futuro do qual nunca poderemos estar certos, sendo a previsão do comportamento da inflação, no longo prazo, mera especulação. Para contornar tal situação, foi adotada a metodologia de análise de projetos considerando os fluxos de caixa em moeda constante e a taxa de juros reais, numa tentativa de minimizar as distorções provocadas pelo fenômeno inflacionário.

Apesar do fato de o método ter permitido a utilização dos modelos da Engenharia Econômica em ambientes inflacionários, uma antiga deficiência presente nos modelos clássicos ficou exacerbada, tendo surgido uma nova e aparentemente pouco estudada distorção.

A análise de projetos por parte de empresa lucrativa, sujeita ao pagamento do imposto de renda, deveria ser elaborada depois do imposto.

Os modelos clássicos da Engenharia Econômica admitem taxa de juros fixa durante a vida do projeto. Isso, sem dúvida, é uma deficiência, uma vez que, sendo o juro o preço do aluguel de uma riqueza, estará sujeito às condições do mercado de capitais, as quais normalmente não se mantêm constantes no decorrer do tempo. Pois bem, se isso é verdade para um ambiente sem inflação, a situação fica muito pior em um ambiente inflacionário, em que a taxa de juros reais normalmente é conhecida a posteriori, por meio da depuração da taxa de juros nominais (taxa aparente) pela taxa de inflação, o que normalmente favorece uma maior variação da taxa real. Essa antiga deficiência vem sendo parcialmente contornada pela análise de sensibilidade à variação da taxa de juros reais, que consiste em analisar a decisão para diferentes níveis de taxas de juros, admitindo, porém, em cada caso, uma taxa fixa durante a vida do projeto.

Além da maior variabilidade da taxa de juros, uma nova deficiência foi introduzida com a prática de se trabalhar com moeda constante e juros reais. Em algumas situações, a hipótese de valores em moeda constante não se sustenta na prática. $\mathrm{O}$ caso mais comum são as análises efetuadas depois do imposto de renda, quando as despesas de depreciação, de acordo com a legislação vigente, são calculadas tomando-se por base o valor original do 
investimento, que está expresso em moeda da data da aquisição, moeda essa, portanto, desvalorizada pela inflação nas datas dos efetivos lançamentos contábeis. Tal circunstância, em última análise, penaliza os investimentos passíveis de depreciação (praticamente todos, com exceção dos terrenos) em virtude de a desvalorização monetária das despesas de depreciação não permitir a total recuperação do desembolso inicial.

\section{EFEITOS DO IMPOSTO DE RENDA NA ANÁLISE DE PROJETOS}

A análise de projetos por parte de empresa lucrativa, sujeita ao pagamento do imposto de renda, deveria ser elaborada depois do imposto. Teoricamente, porém, as análises após o pagamento do imposto só seriam necessárias quando o tratamento fiscal das alternativas dos investimentos fosse diferente. Caso contrário, os efeitos seriam proporcionais em todas as alternativas (Hummel e Taschner, 1995, p. 106).

Algumas considerações importantes devem ser feitas nas análises realizadas depois do imposto de renda (IR), aqui entendido, de uma maneira ampla, como todos os impostos incidentes sobre o lucro, o que engloba, além do IR propriamente dito, a contribuição social e outros eventuais adicionais.

Assim, para se considerar os efeitos do IR nas análises econômicas, é mister ajustar todas as receitas e despesas do projeto, bem como a própria taxa de juros reais, pelo percentual de IR que incide sobre o lucro marginal, doravante chamado de alíquota marginal $\left(a_{m}\right)$.

Considerando que toda receita contábil $(R C)$ do projeto aumenta a base para o pagamento do IR, ocasionando uma despesa, pode-se concluir que a receita líquida depois do imposto poderá ser obtida da seguinte maneira:

$R C \times\left(1-a_{m}\right)$

De modo análogo, toda despesa contábil $(D C)$ reduz a base para o pagamento do IR, gerando, por assim dizer, uma "receita" (economia) de IR, sendo a despesa líquida depois do imposto obtida como se segue:

$$
D C \times\left(1-a_{m}\right)
$$

Os desembolsos com investimentos não são considerados como despesas contábeis, não sendo, portanto, afetados pela incidência do IR. Entretanto, as despesas de depreciação, embora não impliquem saí- das de caixa, reduzem o IR a pagar. Assim, as economias de IR provocadas pelas despesas de depreciação $(D p)$ devem ser tratadas como "receitas" nas datas do seu efetivo lançamento contábil da seguinte forma:

$D p \times a_{m}$

Finalmente, segundo Bierman Jr. e Smidt (1993, p. 252), as despesas de juros são dedutíveis do IR. Dessa maneira, a taxa de juros reais deve ser calculada depois do IR $\left(r_{d}\right)$, a partir da taxa de juros reais antes do IR $\left(r_{a}\right)$, como demonstrado a seguir:

$$
r_{d}=r_{a} \times\left(1-a_{m}\right)
$$

\section{CONSIDERAÇÕES SOBRE A ANÁLISE COMPRA VERSUS ALUGUEL}

O caso clássico da análise compra versus aluguel é bastante afetado pela incidência do imposto de renda. Desse modo, na opção aluguel, todo pagamento realizado é considerado como despesa para efeitos fiscais e, na opção compra, admite-se que somente a depreciação seja considerada como tal.

Para contornar os efeitos da inflação, a Engenharia Econômica utiliza o artifício de trabalhar com valores expressos em moeda de uma mesma data (moeda constante), hipótese que pressupõe que todos os pagamentos e recebimentos futuros sejam, de certa maneira, corrigidos pela inflação. Apesar do fato de que possa haver distorções no curto prazo, em longo prazo, a hipótese é bastante razoável. O que ocorre, entretanto, é que a atual legislação fiscal não permite que os bens do ativo imobilizado sejam atualizados monetariamente, o que, em última análise, significa que, se houver inflação, os valores reconhecidos como depreciação, por estarem monetariamente desvalorizados por ocasião do seu efetivo lançamento contábil, não recuperarão o valor do investimento inicial.

Tal circunstância irá aumentar o valor presente do custo do investimento após o imposto de renda e, conseqüentemente, penalizar a opção compra. Dessa forma, é interessante a escolha do caso clássico compra versus aluguel para a análise dos efeitos da não-atualização monetária dos investimentos, uma vez que as distorções ficam ampliadas em virtude das diferenças no tratamento fiscal.

O caso a seguir pretende ilustrar os problemas que a legislação vigente trouxe para a Engenharia Econômica e para a praxe comum de se trabalhar 
com fluxos de caixa em valores constantes e juros reais, desconsiderando os efeitos da inflação.

\section{O CASO}

Um fabricante de PABX oferece a seus clientes as opções de compra ou aluguel do equipamento.

$\mathrm{O}$ valor do aluguel mensal é definido como um percentual $(3,0 \%)$ do preço do equipamento, e o contrato, de cinco anos, prevê cláusula anual de reajuste de acordo com a variação do índice de preços. No preço do aluguel, encontram-se embutidas as despesas com a manutenção do PABX, mas, se a empresa cliente optar pela compra, deverá assinar um contrato de manutenção que implicará o pagamento de uma taxa mensal de $0,25 \%$ do preço do equipamento, também com cláusula de correção monetária anual.

A empresa cliente é lucrativa e está sujeita ao pagamento do imposto de renda sobre o lucro real, sendo a alíquota marginal de $40 \%$. Por se tratar de equipamento considerado bem de informática, a taxa anual de depreciação, para efeitos fiscais, é de $20 \%$; o horizonte de planejamento para substituição é de cinco anos, e o valor residual do PABX, ao final desse prazo, é admitido nulo, diante da obsolescência tecnológica.

Sendo a taxa real mínima de atratividade da empresa cliente, antes do imposto de renda, admitida em $20 \%$ a.a., que decisão deveria ser tomada: comprar ou alugar o PABX?

\section{SOLUÇÃO CONVENCIONAL}

\section{Premissas}

O método usual da Engenharia Econômica para a solução desse tipo de problema adota como premissas básicas:

a) fluxo de caixa em valores expressos em moeda constante;

b) taxa de juros reais: o que dá consistência à premissa anterior, uma vez que os juros nominais são ajustados para a retirada dos efeitos inflacionários;

c) convenção de "fim de ano", em que todas as receitas e despesas ocorrem no fim de cada ano. Segundo Hummel e Taschner (1995, p. 53), a convenção é válida para os propósitos práticos, pois não conduziria a erros na decisão de alternativas. É evidente que taxas mensais de juros reais ou de inflação muito elevadas causariam distorções, o que se admite que não será o caso das análises efetuadas no presente artigo.

\section{Cálculo da taxa de juros reais após o imposto de renda}

Em se tratando de alternativas em que os efeitos do IR são fundamentalmente diversos, a análise deve ser efetuada após o imposto e, dessa forma, a taxa de juros reais deve necessariamente ser ajustada, conforme exposto na seção "Efeitos do imposto de renda na análise de projetos" e demonstrado a seguir.

Taxa anual de juros reais antes do IR:

$$
r_{a}=0,2(20 \% \text { a.a. })
$$

Alíquota marginal de IR:

$$
a_{m}=0,4(40 \%)
$$

Taxa anual de juros reais depois do IR:

$$
r_{d}=r_{a} \times\left(1-a_{m}\right)=0,2 \times 0,6=0,12(12 \% \text { a.a. })
$$

\section{Análise da opção compra}

$\mathrm{Na}$ análise convencional, os efeitos inflacionários são desconsiderados, uma vez que, caso exista inflação, o uso de taxa de juros reais e moeda constante resolveria a situação. No entanto, em virtude da nãocorreção do valor do investimento (vide seção "Inflação e Engenharia Econômica"), tal premissa estaria necessariamente inviabilizada. Assim, a solução irá, inicialmente, admitir a hipótese simplificadora da inexistência de inflação em todo o período de análise.

$$
\begin{array}{lc}
\text { Investimento inicial: } & 100 \\
\begin{array}{l}
\text { Depreciação anual: } \\
\text { Economia anual de IR }
\end{array} & 20 \\
\begin{array}{l}
\text { devido à depreciação: } \\
\text { Manutenção mensal } \left.{ }^{*}\right)
\end{array} & 0,4 \times 20=8 \\
\begin{array}{l}
{ }^{*} \text { Sem prejuízo da análise comparativa, essa despesa } \\
\text { poderá ser desconsiderada em ambas as alternativas. }
\end{array}
\end{array}
$$

O esquema do fluxo de caixa da opção compra pode ser visualizado na Figura 1.

Figura 1 - Esquema do fluxo de caixa da opção compra

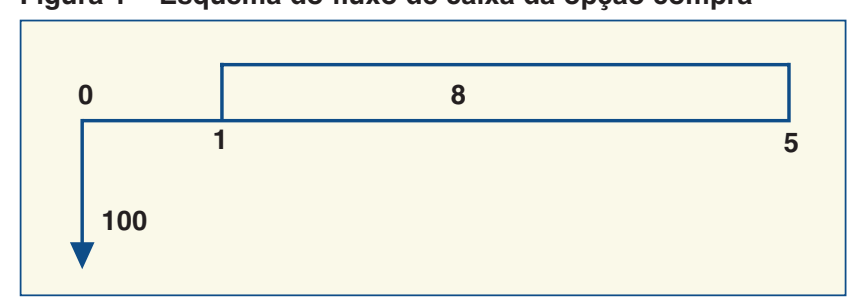




\section{Cálculo do valor presente do custo da opção compra}

Observação: nas indicações de cálculos que utilizam as funções da matemática financeira, foi utilizada a convenção mista HP-Excel (Álvares, 1998b).

$$
\begin{aligned}
& V P C=-100+V P(i=12 \% ; n=5 ; P M T=-8) \\
& V P C=-100+28,8 \\
& V P C=-71,2
\end{aligned}
$$

\section{Análise da opção aluguel}

Aluguel mensal, excluídas as despesas com manutenção:

\section{$3-0,25=2,75$}

Despesas anuais com aluguel antes do IR:

\section{$2,75 \times 12=33$}

Despesas anuais com aluguel após o IR:

$33 \times 0,6=19,8$

O esquema do fluxo de caixa da opção aluguel pode

\begin{tabular}{|c|c|c|}
\hline 0 & 1 & \\
\hline & & 19,8 \\
\hline
\end{tabular}
ser observado na Figura 2.

Figura 2 - Esquema do fluxo de caixa da opção aluguel

Cálculo do valor presente do custo da opção aluguel

$$
\begin{aligned}
& V P A=V P(i=12 \% ; n=5 ; P M T=19,8) \\
& V P A=-71,4
\end{aligned}
$$

\section{Escolha}

Conforme constatado, a opção compra, nas condições propostas, seria ligeiramente mais vantajosa, por ter custo menor. A diferença, no entanto, é pequena o suficiente para as alternativas serem consideradas equivalentes. Aparentemente, o fabricante do equipamento estaria trabalhando com a mesma taxa real de atratividade de $20 \%$ a.a. antes do IR (12\% a.a. após o IR).

\section{ANÁLISE DE SENSIBILIDADE À VARIAÇÃO DAS TAXAS DE JUROS REAIS}

\section{Cálculo da taxa a partir da qual a opção aluguel passa a ser vantajosa}

A opção compra, por significar desembolso inicial elevado e recuperação (economia de IR pela depreciação) ao longo da vida do equipamento, tem o valor presente do seu custo tanto menor quanto menor for a taxa de juros reais. A opção aluguel, por outro lado, ao apresentar desembolso parcelado ao longo do período, tem o valor presente do seu custo reduzido, com o aumento da taxa de juros reais.

Genericamente, o gráfico dos módulos dos valores presentes dos custos das duas opções tem o aspecto demonstrado na Figura 3.

Figura 3 - Gráfico dos módulos dos valores presentes dos custos das opções compra e aluguel

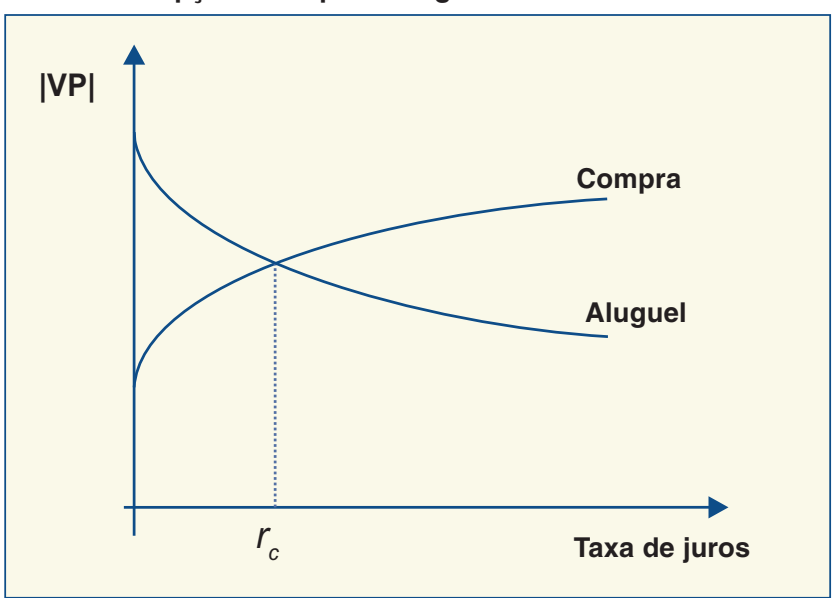

\section{Taxa de corte}

Será definida como taxa de corte $(r)$ a taxa real de juros em que o valor presente do custo da opção aluguel é igual ao da compra. Como conseqüência, o valor presente do fluxo de caixa da diferença (fluxo incremental) deve ser igual a zero.

A determinação de $r$ pode, então, ser feita com o cálculo da taxa interna de retorno do fluxo de caixa incremental (Figura 4).

Figura 4 - Esquema do fluxo de caixa incremental (compra - aluguel)

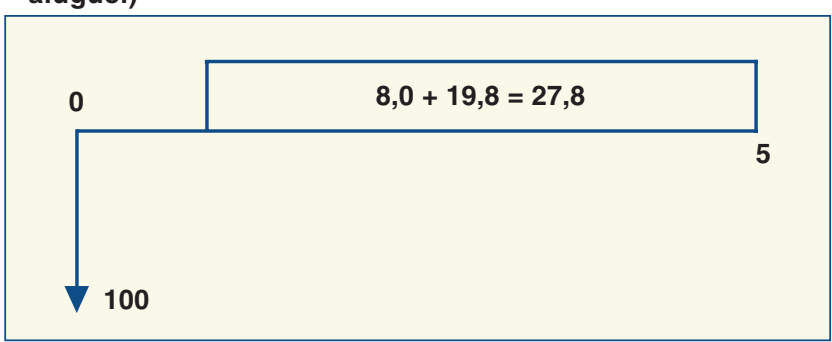


$\mathrm{O}$ esquema da Figura 4 produz a seguinte taxa interna de retorno:

$T I R=12,1 \%$

Dessa forma, a taxa anual de juros reais depois do IR é de:

$$
r_{d}=12,1 \%
$$

Já a taxa anual antes do IR a partir da qual a opção aluguel passaria a ser vantajosa nas condições do problema é de:

$$
r_{a}=\frac{r_{d}}{\left(1-a_{m}\right)}=\frac{0,121}{(1-0,4)}=0,202 \Rightarrow r_{a}=20,2 \% \text { a.a. }
$$

O gráfico da Figura 5 indica os valores presentes dos custos das opções compra e aluguel em função das taxas de juros reais e foi obtido em microcomputador com o auxílio do software MS Excel 7.0 (Ramalho, 1998), sendo bastante ilustrativo.

Figura 5 - Valores presentes em diferentes taxas de juros reais

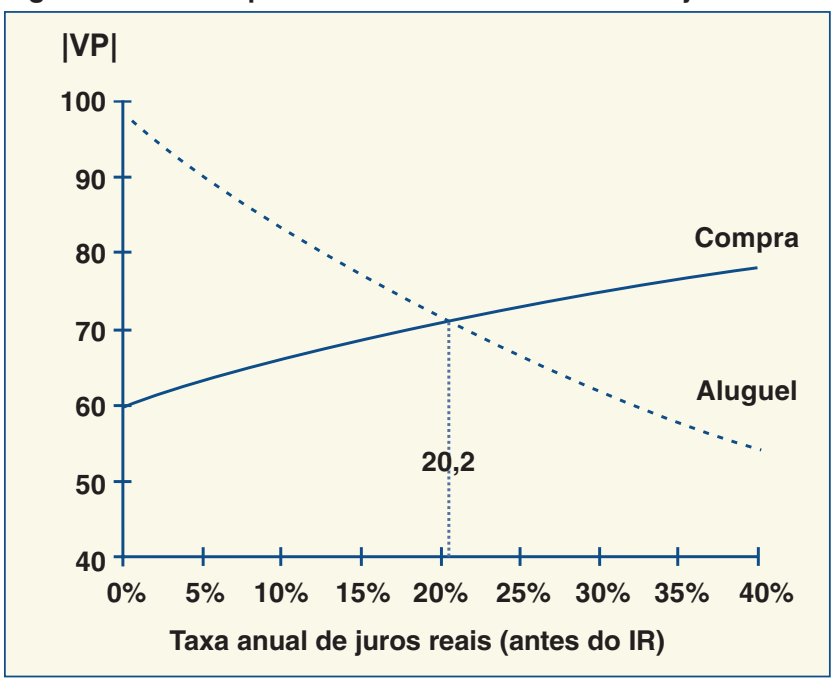

\section{OS EFEITOS DA INFLAÇÃO}

\section{Considerações iniciais}

Conforme já comentado, o fenômeno inflacionário é contornado pela Engenharia Econômica trabalhando-se os fluxos de caixa em moeda constante e utilizando-se taxas de juros reais. No entanto, como a legislação fiscal atualmente em vigor aboliu a correção monetária do balanço, em termos reais, as empresas acabam deduzindo como despesas de depreciação um montante menor do que aquele que foi originalmente desembolsado como investimento.

Particularmente no caso das análises do tipo compra versus aluguel, tal situação poderá conduzir a significativas distorções. Para evitá-las, a alternativa é considerar os efeitos inflacionários no fluxo de caixa.

Desse modo, a seguir, é realizada a análise de sensibilidade à variação da taxa de inflação. Para facilitar os cálculos, admitiu-se a hipótese de que, em cada cenário, a taxa de inflação anual permanecesse constante em todo o período.

\section{Opção compra}

Não havendo a possibilidade de se corrigir o valor do investimento inicial, a depreciação, quando for lançada como despesa fiscal, terá a sua expressão monetária desvalorizada pelo efeito inflacionário.

Supondo-se um ano genérico $j$, sendo $k$ a taxa anual de inflação (considerada constante) e $D p \times a_{m}$ o valor da economia anual de IR em virtude da depreciação, o qual, devido à ausência da correção monetária, estaria expresso em moeda da data $j$, esse mesmo valor, expresso em moeda da data 0 , seria obtido pela expressão:

$$
\frac{D p \times a_{m}}{(1+k)^{j}}
$$

Admitindo-se que a legislação fiscal não sofra alterações durante a vida do equipamento (ou seja, que a alíquota marginal $a_{m}$ e a despesa anual de depreciação $D p$ permaneçam constantes) e considerando-se que cada parcela anual da economia de IR em virtude da depreciação deverá ser trazida a valor presente pela taxa anual de juros reais após o IR, $r_{d}$, obtém-se o valor presente das economias anuais de IR:

$$
\sum_{j=1}^{n} \frac{D_{p} \times a_{m}}{\left(1+r_{d}\right)^{j} \times(1+k)^{j}} \Rightarrow \sum_{j=1}^{n} \frac{D_{p} \times a_{m}}{\left[\left(1+r_{d}\right) \times(1+k)\right]^{j}}
$$

Assim, basta utilizar a função financeira do valor presente de uma série uniforme, fazendo:

$$
1+i=\left(1+r_{d}\right) \times(1+k) \Rightarrow i=\left(1+r_{d}\right) \times(1+k)-1
$$

Dessa forma, a expressão do valor presente da opção compra, levando-se em conta os efeitos da inflação nas economias anuais de IR, será:

$V P C=-100+V P\left(i=\left(1+r_{d}\right) \times(1+k)-1 ; n=5 ; P M T=-8\right)$ 


\section{Opção aluguel}

No caso do aluguel, há correção monetária anual por efeito do contrato, o que leva à hipótese simplificadora de que os fluxos de caixa se encontram em valores constantes. A rigor, a admissão de tal hipótese prejudica a opção aluguel, já que os valores pagos mensalmente sofreriam os efeitos da desvalorização da moeda antes do reajuste anual. O objetivo do presente estudo, porém, não é analisar a vantagem de um aluguel fixo em um regime inflacionário, e sim comparar a situação do investimento (compra) em diferentes condições de inflação.

Assim, será admitido, para a opção aluguel, que o fluxo de caixa se encontra em valores constantes, situação que, na prática, equivale a admitir sua correção mensal, e não anual. Em tal condição, os resultados obtidos permaneceriam sempre constantes, independentemente das variações nas taxas de inflação.

De modo análogo ao caso anterior, obtém-se o ábaco representado na Figura 6, que contempla diversas curvas do valor presente do custo da opção compra, conforme a variação das taxas anuais de inflação, com indicação das taxas de corte a partir das quais, em cada situação, a opção aluguel passaria a ser vantajosa em relação à compra.

\section{CONCLUSÃO}

Atualmente, com a evolução da microinformática, as análises múltiplas de sensibilidade podem ser feitas com certa facilidade. No presente caso, foram combinadas as análises de sensibilidade da decisão compra versus aluguel relativamente à variação das taxas de juros reais e às taxas de inflação a fim de avaliar o efeito da não-atualização monetária do investimento e, à semelhança dos modelos da Engenharia, foi construído um ábaco de múltiplas variáveis.

Conforme se pode observar, há uma penalidade para os gastos com investimentos, em virtude de a desvalorização monetária da depreciação não permitir a total recuperação do desembolso inicial. Assim, na condi-
Figura 6 - Valores presentes em diferentes taxas de juros reais

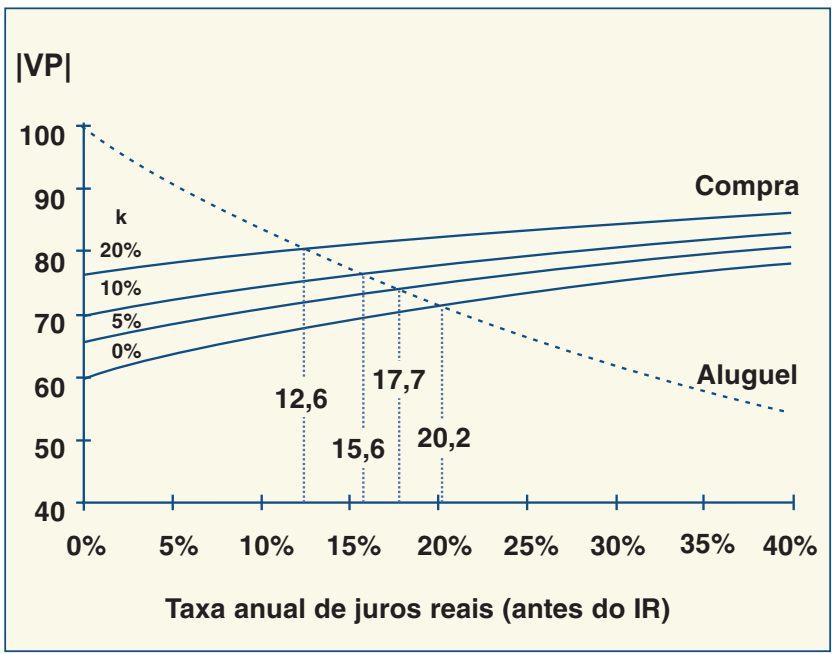

ção de inflação zero, a taxa de juros reais antes do IR em que a opção aluguel (com reajuste mensal) passa a ser vantajosa é de $20,2 \%$ a.a.; já no caso de uma taxa de inflação anual de $20 \%$, a mesma taxa de corte cai para $12,6 \%$ a.a.

A impossibilidade de atualização monetária das despesas de depreciação introduz uma importante deficiência no artifício de desprezar os efeitos inflacionários utilizando-se moeda constante e juros reais nos casos em que a empresa é sujeita ao pagamento de imposto de renda. Havendo inflação, duas importantes conclusões podem ser expostas sobre a análise de investimentos para esse tipo de empresa:

a) as análises de projetos de investimentos devem ser sempre realizadas depois do imposto de renda;

b) devem ser feitas previsões de inflação para o cálculo correto do valor presente das economias de IR produzidas pelas despesas de depreciação. Como a previsão da inflação futura está sempre sujeita a forte incerteza, é conveniente a realização de análises de sensibilidade à variação das taxas inflacionárias. $\bigcirc$
REFERÊNCIAS BIBLIOGRÁFICAS

ÁLVARES, Antonio Carlos Teixeira. Engenharia econômica e inflação. São Paulo, 1998a. Material interno da FGV/EAESP, PG 0051-LI, 20 p.

ÁLVARES, Antonio Carlos Teixeira. Convenções para funções financeiras. São Paulo, 1998b. Material interno da FGV/EAESP, PG-0046-LI
BIERMAN JR., Haroldo, SMIDT, Seymour. The capital budgeting decision: economic analysis of investment projects. 8. ed. New Jersey : Prentice-Hall, 1993. 591 p.

FMI. Estadísticas financieiras internacionales: anuario. Washington : El Fondo, 1998. V. L1.

HUMMEL, Paulo Roberto Vampré, TASCHNER, Mauro Roberto Black. Análise e decisão sobre investimentos e financiamentos: engenharia econômica - teoria e prática. 4. ed. São Paulo : Atlas, 1995. 216 p.

JONES, Byron W. Inflation in engineering economic analysis. New York : John Wiley \& Sons, 1982. 216 p.

RAMALHO, José Antonio. Excel 97. São Paulo : Makron Books 1998. $301 \mathrm{p}$ 